\title{
A CONSTRUÇÃO DE UMA IDENTIDADE DOCENTE DESEJÁVEL NO DISCURSO DO MOVIMENTO ESCOLA SEM PARTIDO
}

\author{
THE CONSTRUCTION OF A DESIRABLE TEACHING IDENTITY IN THE SPEECH OF THE MOVEMENT ESCOLA SEM PARTIDO
} (NO-PARTY SCHOOL)

\author{
LA CONSTRUCCIÓN DE UNA IDENTIDAD DOCENTE DESEABLE EN EL DISCURSO DEL MOVIMIENTO ESCUELA SIN \\ PARTIDO
}

\author{
KATZ, Elvis Patrik 1 \\ MUTZ, Andresa Silva da Costa ${ }^{2}$
}

\section{RESUMO}

O movimento social Escola Sem Partido vem se notabilizando, nos últimos anos, pelo ataque sistemático aos profissionais da educação. O presente texto tem por objetivo apresentar, a partir das teorizações do pensamento de Michel Foucault e das contribuições dos Estudos Culturais, que as enunciações proferidas pelo movimento em seus mais diversos materiais constituem-se numa vontade de governo sobre as identidades docentes. O ESP procura representar os docentes tidos como desejáveis, bem como erigir fronteiras bem demarcadas para fiscalizar e condenar os chamados professores "doutrinadores".

Palavras-chave:Escola Sem Partido. Identidade docente. Estudos Culturais. Discurso.

\section{ABSTRACT}

The social movementEscola SemPartido (No-Party School) The No-Party School has been making itself known in recent years by the systematic attack on education professionals. The present text aims to present, from the theories of Michel Foucault's thought and the contributions of the Cultural Studies, that the utterances uttered by the movement in its most diverse materials constitute a will of government over the educational identities. The ESP movement seeks to represent teachers deemed desirable, as well as erect well-demarcated boundaries to supervise and condemn the so-called "doctrinaire" teachers.

Keywords: Escola SemPartido (Non-Party School). Teaching Identity. Cultural Studies. Speech.

\section{RESUMEN}

La Escuelasin Partido se ha destacado enlos últimos años por el ataque sistemático a losprofesionales de laeducación. EI presente texto tiene por objetivo presentar, a partir de lasteorizacionesdelpensamiento de Michel Foucault y de lascontribuciones de losEstudiosCulturales, que lasenunciaciones proferidas por elmovimientoen sus más diversos materiales se constituyenen una voluntad de gobierno sobre las identidades docentes. El movimiento ESP se busca representar a los docentes tenidos como deseables, así como erigir fronterasbien demarcadas para fiscalizar y condenar a losllamadosprofesores "adoctradores".

Palabras clave:EscuelaSin Partido. Identidad docente. EstudiosCulturales. Discurso.

\footnotetext{
1UniversidadeFederal do Rio Frande- FURG - Rio Grande- Rio Grande do Sul - Brasil

${ }^{2}$ UniversidadeFederal do Rio Frande- FURG - Rio Grande - Rio Grande do Sul - Brasil
} 


\section{INTRODUÇÃO}

O presente artigo compõe algumas reflexões decorridas de uma pesquisa em nível de mestrado realizada no Programa de Pós-Graduação em Educação - PPGEDU da Universidade Federal do Rio Grande - FURG ao longo do último ano. Assim, argumento que os ditos do Escola Sem Partido constituem-se em investidas de poder sobre as identidades docentes e tento esmiuçar qual seria o papel da construção de uma identidade docente (in) desejável nessa tarefa. Com isso, o texto foca na tentativa de enxergar, em determinadas enunciações do ESP, como é construída uma identidade docente (in) desejável e quais as principais táticas discursivas do movimento no intuito de governar e produzir identidades a partir dos seus modelos e prescrições. Até chegar nesse ponto, no entanto, é prudente que sejam feitas algumas colocações preliminares. Refiro-me a uma breve explanação das bases teóricas e metodológicas que sustentam o artigo, o que implica num comentário acerca dos usos do pensamento de Michel Foucault e de algumas ferramentas teóricas do campo dos Estudos Culturais. Após, então, me debruço sobre a descrição efetiva das falas proferidas pelo Escola Sem Partido e as conclusões que podemos observar.

\section{ASPECTOS TEÓRICO-METODOLÓGICAS}

Fundado em 1964, na Inglaterra, o Centro de Estudos Culturais Contemporâneos se consolidou como importante suporte às mais variadas pesquisas disseminando um novo tipo de abordagem acerca da cultura pela Europa, América do Norte e, mais recentemente, na América Latina e na África. Inicialmente, a agitação em torno da criação do centro residia na discordância de alguns autores (Raymond Willians e E.P. Thompson, principalmente) com a noção de cultura enquanto sinônimo de cultura da elite. Sendo assim, o grupo possuía forte conotação política, especialmente do campo teórico marxista, dado suas intenções de valorizar a "cultura de massa". Hoje, tanto essas tendências mais politizadas como as concepções pós-modernas coabitam dentro dos EC, o que promove ainda mais seu caráter pouco disciplinar. Contudo, é possível encontrar certa concordância dentro do campo, muito em função da ideia de cultura veiculada por seus autores:

\footnotetext{
De forma talvez mais importante, os Estudos Culturais concebem a cultura como campo de luta em torno da significação social. A cultura é um campo de produção de significados no qual os diferentes grupos sociais, situados em posições diferenciais de poder, lutam pela imposição de seus significados à sociedade mais ampla. A cultura é, nessa concepção, um campo contestado de significação [...] Os Estudos Culturais são particularmente sensíveis às relações de poder que definem o campo cultural (SILVA, 2009, p. 133-134).
}

Assim, os pesquisadores alinhados aos ECfazem uso recorrente de alguns conceitos fundamentais e que são de interesse para o presente trabalho. Em primeiro lugar, as próprias noções de cultura e educação; a primeira como conjunto das verdades, dos discursos, saberes, tradições, que atravessam o tecido social e estão mergulhados em jogos de poder (SILVA, 2009). A segunda entendida como aqueles saberes colocados à disposição de fins específicos, sob a forma de 
conhecimento científico, muitas vezes, com objetivos claros e manifestos de governar os sujeitos; a pedagogia é um exemplo dessa forma sistemática de exercício do poder.

Outro conceito importante é o de identidade cultural. Na esteira de Stuart Hall (2006), compreendo as identidades contemporâneas como múltiplas e dispersas, sem o caráter unitário capaz de aglutinar os interesses dos diversos sujeitos e grupos sociais, como era o caso das identidades nacionais até a Segunda Guerra Mundial. Essas identidades fluidas da contemporaneidade são como papéis sociais exercidos pelos sujeitos e não identidades fixas e eternas. Dessa forma, um professor ou professora não possui apenas a identidade docente, mas também a de gênero, classe, raça, etc. A identidade, portanto, que até bem pouco tempo atrás possuía um viés sociológico bastante marcante, começa a aparecer de maneira fragmentária, o que contraria a ideia moderna do sujeito unificado (HALL, 2006).

Faz-se necessário perceber qu "a" identidade docente é uma categoria difícil de perscrutar. A própria situação da profissionalização docente no Brasil também, na medida em que a função de professor ainda é encarada como um trabalho temporário ou passível de realização por leigos, e não necessariamente por especialistas (BRZEZINSKI, 2002). Ou seja, a própria situação de semiprofissionalização e a dificuldade de articulação política dos movimentos sindicais reforça a identidade pouco sólida dos professores no Brasil. Assim, a noção de identidade docente passa a significar muito mais a coletividade de professores e funciona como certa estratégia dos próprios discursos para homogeneizar as inúmeras diferenças no interior da categoria.

$\mathrm{Na}$ prática, qualquer tentativa de individualizar, separar ou unificar essas identidades é arbitrária, dado que sua principal característica é a heterogeneidade. Gênero, raça, sistemas de ensino, finalidade da escola (privada ou pública), níveis de ensino (infantil, fundamental, médio e superior), características dos estudantes, condições de trabalho, qualificação profissional, interesses; enfim, basta um pequeno exercício de memória e veremos muito mais diferenças do que semelhanças no interior do que se chama de identidade docente.

Essa vontade de centralizar um conceito de identidade que remeta a todos ou a maioria dos professores está presente na própria cultura. Ademais, ela está presente nos discursos que circundam a educação, como os da mídia (revistas, jornais, a televisão, a internet) e as próprias ferramentas de controle do Estado neoliberal (avaliações em larga escala, estudos voltados a produção de estatísticas e "verdades" acerca da educação, etc). Assim, na atualidade se produzem inúmeros discursos que se voltam para identidades específicas e que são, em geral, padronizantes, pois objetivam fabricar identidades dentro de uma normalidade. Acerca dessa normalização das identidades, é possível pensar na transformação que Foucault observa na modernidade, quando o avanço do biopoder levaria a uma espécie de mudança nas leis e que, portanto, "a formação de uma sociedade normalizadora, longe de provocar o apagamento da lei ou o desaparecimento das instituições da justiça, vai antes a par com uma espantosa proliferação legislativa" (EWALD, 1993, p. 78).

Com relação ao que se convencionou chamar de método vou procurar ser bastante breve, seja por economia de espaço ou pelo grande número de trabalhos existentes na área. O tipo de análise feita nesse artigo enquadra-se na categoria de análise do discurso, porém essa tarefa é feita a partir dos operadores teóricos de Michel Foucault. Em sua arqueologia, o autor empreende uma descrição de 
enunciados que visa, em suma, fazer aparecer as práticas discursivas presentes nos mais diversos ditos e escritos. Nas palavras de Rosa Maria Bueno Fischer:

[...] é preciso ficar (ou tentar ficar) simplesmente no nível de existência das palavras, das coisas ditas. Isso significa que é preciso trabalhar arduamente com o próprio discurso, deixando-o aparecer na complexidade que Ihe é peculiar. E a primeira tarefa para chegar a isso é tentar desprender-se de um longo e eficaz aprendizado que ainda nos faz olhar os discursos apenas como um conjunto de signos, como significantes que se referem a determinados conteúdos, carregando tal ou qual significado, quase sempre oculto, dissimulado, distorcido, intencionalmente deturpado, cheio de "reais" intenções, conteúdos e representações, escondidos nos e pelos textos, não imediatamente visíveis (2001, p. 198).

Tudo isso implica, assim, uma atitude frente ao corpus de análise que não se assemelha ao trabalho com as fontes do historiador convencional. Nas próximas páginas, não há nada mais do que uma reescrita, sem a procura por sentidos ocultos ou interpretações que expliquem o que está "por trás" do texto. O que está posto é a ação deliberada de mostrar a constituição de uma formação discursiva com ênfase em seu momento de irrupção, sem confundir isso com a história de uma origem mítica ou verdadeira. De forma muito diferente, o pensamento de Michel Foucault nos oferece ferramentas interessantes para abordarmos práticas discursivas em meio a práticas não discursivas, observando as imbricações entre saber e poder.

\footnotetext{
Temos antes que admitir que o poder produz saber (e não simplesmente favorecendo-o porque o serve ou aplicando-o porque é útil); que poder e saber estão diretamente implicados; que não há relação de poder sem constituição correlata de um campo de saber, nem saber que não suponha e não constitua ao mesmo tempo relações de poder (FOUCAULT, 2010, p. 30).
}

Segundo o filósofo francês, a análise do discurso arqueológica "[...] designa o tema geral de uma descrição que interroga o já dito no nível de sua existência; da função enunciativa que nele se exerce, da formação discursiva a que pertence, do sistema geral de arquivo de que faz parte" (FOUCAULT, 2008, p. 149). Assim, trata-se de "definir os discursos em sua especificidade; mostrar em que sentido o jogo das regras que utilizam é irredutível a qualquer outro; segui-los ao longo de suas arestas exteriores para melhor salientá-los. [É] uma análise diferencial das modalidades de discurso" (2008, p. 157-158). Por fim, cabe mencionar que a análise desse trabalho se debruça sobre os textos publicados pelo Escola Sem Partido que buscavam construir modelos e prescrições de identidades docentes desejáveis e indesejáveis; elas aparecem principalmente sob a forma de artigos de opinião e nas abas "apresentação", "quem somos", "objetivos" e "FAQ" do www.escolasempartido.org e nas abas "saiba mais", "FAQ" e "sobre" do www.programaescolasempartido.org. Para os objetivos desse texto analisaremos apenas as "coisas ditas" dessas abas dos sites indicados, deixando de lado os artigos de opinião presentes no site oficial do movimento.

\section{A IDENTIDADE DOCENTE (IN) DESEJÁVEL NO DISCURSO DO ESCOLA SEM PARTIDO}

Para iniciar a conversa, vale destacar que o Escola Sem Partido, em seus textos, coloca seus posicionamentos gerais acerca dos mais diversos temas relacionados com a educação. São nesses 
ditos descritos ainda na seção anteiror que o movimento se apresenta aos interessados e argumenta sobre suas demandas. Diferentemente dos artigos de opinião, também referidos há pouco, nessas abas não são apresentados os autores, o que indica, certamente, que as enunciações presentes ali devem ser tomadas como bases para o ESP em sua totalidade; ou seja, elas não são apenas falas opinativas que o Escola Sem Partido concorda e assume como suas, mas tem ainda mais importância na medida em que é o ESP quem assume a suas autorias. Nosso critério de seleção e demonstração dos dados reside justamente no objetivo imediato do presente trabalho: quais modelos de identidades docentes são construídas nessas "coisas ditas"? Como é representado o professor indesejável, quais suas características? E, em oposição, como deveria ser o docente desejável, na óptica do Escola Sem Partido? Uma síntese desses modelos está representada na tabela abaixo.

Figura 1: Modelos de identidade docente do Escola Sem Partido

\begin{tabular}{cc}
\hline IDENTIDADE INDESEJÁVEL & IDENTIDADE DESEJÁVEL \\
Crítico (fraude) & Verdadeiro pensamento crítico \\
Militante & $\begin{array}{c}\text { Precauções metodológicas } \\
\text { necessárias para reduzir a distorção } \\
\text { Monopólio ideológico/ldeias de } \\
\text { esquerda } \\
\text { Ciências humanas e educação } \\
\text { (história) } \\
\text { Se aproveita da "audiência cativa" dos de perspectivas } \\
\text { alunos para lhes "fazer a cabeça" }\end{array} \quad \begin{array}{c}\text { Autoridade em sala de aula/Persegue } \\
\text { o ideal de neutralidade }\end{array}$ \\
Aborda temas morais em disciplinas \\
obrigatórias
\end{tabular}

Fonte: Katz (2017, p. 109)

Esses dois polos são úteis para que se possa explicar de maneira didática a forma como o Escola Sem Partido busca governar a conduta docente através de suas investidas de poder. As posições de sujeito exemplificadas na ilustração acima não correspondem, dessa forma, a professores reais, mas a certos limites de atuação que as identidades docentes poderiam, e deveriam, se ajustar. Tal como o processo de normalização (EWALD, 1993), o espaço no interior do desejável e do indesejável deveria ser ocupado pelas identidades existentes, as quais mediriam seu grau de qualidade (na visão do Escola Sem Partido) em função da aproximação e distanciamento de um dos limites. Não quero, portanto, cair num maniqueísmo que separaria os bons dos maus. A figura apenas mostra a 
forma como a organização enxerga, nos seus extremos, os professores a quem visa governar. Tais modelos (desejável e indesejável), assim, servem não apenas como diagnóstico do ponto de vista do movimento, mas como guia do que o Escola Sem Partido espera conseguir a partir de suas investidas de poder.

Nesse sentido, observa-se que há sempre, em primeiro lugar, a descrição do professor indesejável e, após isso, o movimento argumenta em torno do que considera a postura docente desejável. Quer dizer, através da fabricação de verdades acerca do mau professor, o movimento produz identidades opostas que sirvam como alternativas. Por conta disso, decidi apresentar, lado a lado, os pólos presentes na ilustração. Na construção discursiva do Escola Sem Partido, a produção desses modelos só faz sentido em oposição ao seu antagonista. De qualquer forma, a construção da identidade desejável é muito importante, do ponto de vista da análise, pois contrapõe a ideia de que o ESP atue sempre "pela estratégia da subtração: [quando] visualiza algo que está presente na escola, e busca sua retirada, sem exatamente propor a inclusão explícita de outra coisa" (SEFFNER, 2016, p. 09). Ao contrário do que verificou Fernando Seffner, entendo que o Escola Sem Partido não se limita apenas a tentar subtrair elementos considerados "negativos" na prática educativa, mas também coloca aquilo que, na sua perspectiva, deve ser o ideal. Isso tudo pode ser plenamente aceito quando se considera a análise feita em toda a Dissertação. Com isso, o movimento não está apenas interessado em proibir os professores, mas também quer construir suas subjetividades, tal como muitos discursos pedagógicos ou que circundam a educação brasileira (GARCIA; HYPOLITO; VIEIRA, 2005)

Seguindo o raciocínio, mesmo que a maioria dos educadores compreenda a organização ESP como um alienígena, não é menos verdadeiro que ele tenta estabelecer certo diálogo, mesmo que restrito, com o campo pedagógico, como se verificou na Seção 2. Obviamente, o caráter denuncista do movimento implica na inexistência de qualquer debate produtivo, mas isso não significa que o Escola Sem Partido se sinta desobrigado de "prestar contas" do que entende pela educação escolar. Assim, mesmo que seja apenas para justificar suas propostas, eles acabam construindo saberes com fins determinados de produzir realidades e, principalmente, conquistar seguidores na sociedade. Dentro desse "público" focado pela organização, pensando em termos de modos de endereçamento (ELLSWORTH, 2001), encontram-se os professores.

Cada um dos pontos mais significativos demonstrados na ilustração, então, merece atenção. Em primeiro lugar, há a caracterização dos professores "doutrinadores" como aqueles docentes "críticos"; num sentido, essa crítica é apresentada como um pretexto dos "militantes" para ensinar aos alunos "a sua própria visão de mundo" (ESP, IDE 002, 2016). Essa prática representaria, assim, "martelar ideias de esquerda na cabeça dos estudantes" (ESP, IDE 004, 2016). O problema, portanto, residiria no fato de que a crítica feita pelos professores "doutrinadores" ser sempre direcionada aos alvos da direita política, como o capitalismo, a burguesia, a igreja católica, a família, a propriedade privada, os EUA, entre outros. O argumento do movimento é que deveria haver também a crítica aos projetos sociopolíticos da própria esquerda, como "a repressão política e o fracasso econômico da antiga União Soviética" ou "os campos de reeducação e trabalho forçado na China comunista" (ESP, IDE 004, 2016). Enfim, os docentes descritos pelo ESP seriam, no mínimo, críticos parciais e, quando necessário, até mentiriam para encobrir eventuais erros da "esquerda" e crucificar qualquer elemento 
da "direita". Contudo, não se deve simplesmente aceitar essa enunciação do ESP sobre esses docentes como algo dado, senão percebê-la, e isso é o mais importante, como uma espécie de tentativa de convencimento do leitor, no sentido de "mostrar" que o professor crítico é malintencionado.

Contudo, é bastante razoável considerar o argumento de Maria Manuela Alves Garcia (2002), de que os professores que se entendem como representantes de uma ação político-educativa de esquerda também buscam escancarar suas próprias verdades, conscientizar o seu próprio público. Quer dizer, os docentes críticos estabelecem certas relações de poder com seus educandos em nome da emancipação e a tomada de consciência desses sujeitos. Portanto, todas as práticas desse professor se orientam para a verdade, e não para a mentira, como quer fazer crer o Escola Sem Partido. A questão é que, tanto para um lado como para o outro (docentes críticos versus ESP) o que existe é crença que de exista apenas uma verdade ou melhor, a sua verdade, e na melhor das hipóteses, um conjunto de enunciados mais ou menos aceitáveis dentro de certo espectro político e moral. De certa forma, ao lutarem pelos mesmos valores universais, as diferentes perspectivas adotam modos distintos de ver e criticar o mundo.

Em resposta ao "crítico" supostamente fraudulento, a organização propõe que se pratique o "verdadeiro pensamento crítico". Entretanto, ela não especifica em que consiste essa tarefa, mesmo que insinue que tal crítica atuaria de maneira implacável sobre todo e qualquer conhecimento, sem qualquer preferência do professor. Paradoxal, no entanto, é que o próprio Escola Sem Partido não adota tal postura, na medida em que concentra todas as suas forças apenas na problematização da doutrinação "de esquerda", bem como às posturas políticas de partidos e movimentos sociais desse campo ideológico. Com isso, a verdadeira crítica proposta pelo ESP não se diferencia em nada daquilo que ele descreve como inadequado.

Outra caracterização do professor "doutrinador" é que este seria um militante em sala de aula, o qual estaria comprometido com sua prática política cotidiana e que levaria seus posicionamentos para os estudantes como forma de fazer propaganda ao seu partido ou bandeira política. Segundo o movimento, questionar as condutas militantes não significa dizer que o conhecimento deve ser neutro, como muitos têm afirmado, senão que deve haver a busca pela objetividade, o que implicaria na não aceitação de condutas explicitamente comprometidas politicamente. Aqui entra uma controvérsia de grandes proporções: afinal, como se sabe, há toda uma tradição pedagógica "de esquerda" ancorada a partir de uma crítica a ideia de neutralidade política e que defende abertamente a necessidade de posicionamento ideológico dos professores. Em geral, essa tradição assume que a própria tentativa de buscar a neutralidade significa assumir um lado político e, nesse sentido, seria melhor ter consciência (sic) das suas práticas pedagógicas enquanto atos políticos do que simplesmente perseguir uma imparcialidade impraticável. Novamente a discussão ficaria mais longa aqui, pois se os dois lados possuem suas "verdades" é improvável que um debate mais produtivo possa ser estabelecido. Mesmo assim é interessante, mais uma vez, ver as aproximações que podem ser feitas entre esses discursos. A própria ideia de "precauções metodológicas" que é usada para permitir a objetividade, foi importada da ciência, conforme argumentei, um campo de saber que tanto as tradições críticas/marxistas quanto os (neo) liberais buscam reivindicar o direito de representar. 
Um terceiro ponto importante é o do "monopólio ideológico" das "ideias de esquerda" que existiria no sistema de ensino. Para o Escola Sem Partido, como reiterado inúmeras vezes, a esquerda é não apenas a responsável por empreender a doutrinação, mas por apoiá-la e acobertá-la. Assim, um aspecto fundamental do pensamento do ESP não pode ser esquecido: a suposta luta contra um adversário institucional, um "Estado autoritário", que representasse a esquerda. Esse argumento foi um dos grandes aliados para o próprio crescimento da organização. Ao promover, em conjunto com os intelectuais da direita, a crítica aos Governos do PT (de Lula e Dilma), o movimento não questionava apenas alguns casos isolados de professores inescrupulosos com intenções duvidosas sobre os estudantes; inversamente, ao apontar para a "doutrinação" como um problema do Governo brasileiro, em que os órgãos do Estado seriam parte de um plano muito maior de controle social, os partidários do ESP conseguiram ser muito mais eficientes nas suas práticas de governo e subjetivação colocadas. Esse caminho escolhido é, inclusive, muito fácil de ser compreendido, tendo em vista que os movimentos sociais em geral acabam sendo mais fortes e angariam mais seguidores quando se pode enxergar um grande inimigo que "oprime" os cidadãos, como foi no Regime Militar. Não é por acaso que entre os movimentos estudantis e sociais da Ditadura e os da Nova Democracia há diferenças grandes, entre as quais a amplitude dos atos promovidos.

Como solução para essa "hegemonia da esquerda", o Escola Sem Partido argumenta para "que as escolas adotem medidas concretas para assegurar a diversidade de perspectivas ideológicas nos seus respectivos corpos docentes. Afinal, em matéria de conhecimento, o pior dos mundos é o do monopólio ideológico" (ESP, IDE 003, 2016). Essa posição é emblemática e remete a alguns problemas de método que poderiam derivar dela. Por mais que eu tenha assumido uma postura foucaultiana que examina as enunciações no nível do "já dito", isso não resulta que se aceite tudo como certo. Ao contrário de recusar tudo de antemão, não quero também que esse trabalho pareça um panfleto do movimento. Ou seja, ao fim e ao cabo não interessa saber se o que o Escola Sem Partido diz é verdadeiro, mas perceber como ele se utiliza da verdade para exercer sua vontade de poder/governo através da produção de modelos identitários docentes. Assim, não se torna necessário averiguar se "realmente" o movimento é pluralista, democrático ou respeitoso com as opiniões diversas, como ele pretende se apresentar. Urgente, no entanto, é indicar que o pluralismo, a democracia e o respeito são a todo momento objeto de disputa em nossa sociedade, pois não faltam enunciados que reivindiquem serem os verdadeiros possuidores de determinado bem cultural: assim são os discursos pedagógicos (ou extra-pedagógicos) contemporâneos, entre eles o do ESP.

A quarta descrição de modelo feita no corpus diz respeito às disciplinas ou áreas de conhecimento em que, do ponto de vista do Escola Sem Partido, a "doutrinação" seria mais frequente. Dessa forma, encontram-se várias menções ao fato de que nas "áreas de educação, ciências humanas e sociais que as práticas e conteúdos doutrinadores se manifestam de forma mais explícita e ostensiva" (ESP, IDE 004, 2016). Isso ocorreria porque esses campos de conhecimento abordariam frequentemente temáticas relacionadas a política; a manifestação mais repetida dentro dessas práticas seria a preeminência no uso de obras literárias "de esquerda" e críticas que tenderiam a atacar o capitalismo. Novamente aqui, se aponta para o "unilateralismo" da crítica "de esquerda". Contudo, apesar do ESP detectar que nessas áreas a "distorção" do conhecimento é maior, não há, 
explicitamente, a indicação de que nas ciências exatas ou naturais, por exemplo, a objetividade ocorra de maneira mais tranquila. Sobre esse assunto, é digno de nota que essa demarcação das ciências humanas como lócus da "doutrinação" é ainda mais intensa e se manifesta mais extensivamente na disciplina de história e nos usos eventuais do passado como arma política. Tal campo seria uma das ferramentas prediletas da "militância de esquerda".

Outra construção discursiva do ESP refere-se ao professor que se aproveitaria da sua posição de "autoridade" para "fazer a cabeça" dos alunos. Com isso eles querem afirmar que, sendo o ensino obrigatório no Brasil, os estudantes não estariam em condições de recusar quaisquer ensinamentos vindos dele. Ou seja, tal como nas disciplinas optativas do currículo, em geral se evoca a disciplina de Ensino Religioso, determinadas temáticas abordadas pelo professor indesejável extrapolariam alguns limites. Essas barreiras que a escola ou o professor não poderiam transgredir, segundo o Escola Sem Partido, seriam determinadas pela família ou a própria religião do estudante. A respeito disso:

As conexões entre moral e religião, e a manifesta impossibilidade de que se possa ter uma moral republicana, constituem uma questão forte da argumentação [...] Religião e família parecem constituir as únicas fontes para o estabelecimento de princípios morais, e vale dizer que postas assim, no singular, ou seja, uma dada religião, que fica sempre suposta como a católica, e uma dada família, sempre suposta a família monogâmica heterossexual (SEFFNER, 2016, p. 10).

Segundo Seffner, portanto, haveria no cerne do pensamento do movimento uma forte valorização das instituições familiares e religiosas, e um consequente decréscimo da função do Estado na educação dos jovens. Luís Felipe Miguel (2016) vai na mesma linha ao afirmar que os ditos do ESP ignoram o caráter republicano da escola e afirmam a soberania da família no processo educativo das crianças e adolescentes. Segundo a organização, os professores deveriam perseguir o ideal da neutralidade obedecendo aos preceitos familiares dos estudantes. Poder-se-ia dizer que o Escola Sem Partido "reinstala certa visão de que a educação é um processo eminentemente técnico" (SEFFNER, 2016, p. 09), de modo semelhante ao modelo educativo cultivado pelo Estado durante a Ditadura CivilMilitar. A questão é que, do ponto de vista do movimento, os alunos são mesmo tomados como objetos passivos capazes de manipulação total por parte dos docentes, como deixei claro nos capítulos precedentes. Daí o paradoxo que, dentre as medidas colocadas pelo ESP, esteja um cartaz afixado nas salas de aula com os "Deveres do Professor". Quer dizer, como podem ser os estudantes, ao mesmo tempo, vítimas incapazes de se defender da "doutrinação" (essa é a justificativa contida nos PL's) e responsáveis por fiscalizar a prática docente? Sendo eles incapazes, como poderiam saber quando a doutrinação ocorre? E, ao contrário, se fossem hábeis em decifrar a "doutrinação", porque haveria a necessidade das leis ou, menos ainda, para quê serviria o próprio movimento? Enfim, questão interessante para ser aprofundada pelos críticos da organização. 


\section{CONSIDERAÇÕES FINAIS}

A título de conclusão, viu-se que a produção da identidade docente (in) desejável passa pela definição de um professor que é "crítico" e busca "despertar a consciência crítica" dos seus estudantes. "Militante", esse docente defende principalmente "ideias de esquerda", "freireanas" ou "marxistas", dado que pertence a um "monopólio ideológico" que pratica a "doutrinação" com apoio estatal. São docentes predominantemente das áreas das ciências humanas e da educação, em especial da disciplina de História, e pertencentes à rede pública de ensino, nos mais variados níveis (fundamental, médio e superior). Com isso em mente, seria possível supor também que essas definições feitas pelo Escola Sem Partido buscam demonstrar, de alguma forma, como deveriam ser os docentes contemporâneos, no intuito de governar esses sujeitos através da oferta de posições de sujeito, ou modelos, a serem ocupados ou recusados de maneira ativa. Esse processo não ocorre de forma simples, mas parece certo afirmar que, mesmo que se discorde frontalmente das posições do ESP, a fabricação de sentidos empreendida pelo movimento pode ser muito efetiva ao oferecer exemplos negativos e positivos de atuação docente. É importante que trabalhos de análise como esse sejam realizados para poder mostrar como operam esses discursos, quais táticas utilizam e em quais domínios procuram concentrar seus esforços. Tais estudos possibilitariam ofertar ferramentas aos professores que se interessam pela temática e, mais ainda, instrumentos de resistência profissional a projetos baseados em ideias oriundas desses porta-vozes.

\section{REFERÊNCIAS}

1. BRZEZINSKI, Iria. Profissão Professor: Identidade e Profissionalização docente. Brasília: Plano, 2002.

2. EWALD, François. Foucault e a norma. In: EWALD, François. Foucault, a norma e o direito. Lisboa: Veja, p. 77-125, 1993.

3. FISCHER, Rosa Maria Bueno. Foucault e a análise do discurso em educação. Cadernos de Pesquisa. Rio de Janeiro, n. 114, p.197-223, 2001.

4. FOUCAULT, Michel. A Arqueologia do Saber. Tradução: Luiz Felipe Baeta Neves, 7ed. Rio de Janeiro: Forense Universitária, 2008.

Vigiar e punir: nascimento da prisão. Tradução de Raquel Ramalhete. 38 ed. Petrópolis: Vozes, 2010. 
6. ELLSWORTH, Elizabeth. Modos de endereçamento: uma coisa de cinema; uma coisa de educação também. In: SILVA, Tomaz Tadeu da. Nunca fomos humanos - nos rastros do sujeito. Belo Horizonte: Autêntica, 2001

7. ESCOLA SEM PARTIDO. FAQ (IDE 004). $2016 . \quad$ Disponível em:<http://escolasempartido.org/planeje-sua-denuncia>. Acesso em: 14 Nov. 2016.

FAQ. Programa Escola Sem Partido (IDE 006). 2016. Disponível em:<http://www.programaescolasempartido.org/FAQs>. Acesso em: 26 Jul. 2016.

Planeje sua Denúncia(CON 006). 2016. Disponível
em:<http://escolasempartido.org/planeje-sua-denuncia>. Acesso em: 14 Nov. 2016.

10. Saiba mais/Sobre em:<http://www.programaescolasempartido.org/saiba-mais>. Acesso em: 26 Jul. 2016
Disponível

em:<http://WwW.programaescolasempartido.org/saiba-mais $>$. Acesso em: 26 Jul. 2016.

11. GARCIA, Maria Manuela Alves. O mestre pastoral crítico. In: Pedagogias críticas e subjetivação: uma perspectiva foucaultiana. 1. ed. Petrópolis: Vozes, 2002. v. 1. 188 p.

12. GARCIA, Maria Manuela Alves; HYPOLITO, Álvaro Moreira; VIEIRA, Jarbas Santos. As identidades docentes como fabricação da docência. Educação e Pesquisa, v. 31, n. 1, p. 45-56, 2005.

13. KATZ, Elvis Patrik. Escola Sem Partido: Uma análise das investidas de poder sobre as identidades docentes. 2017. 142f. Dissertação (Mestrado em Educação) - Universidade Federal do Rio Grande. Rio Grande, 2017. Disponível em: <https://argo.furg.br/?BDTD11673>. Acesso em: 03 Ago. 2018.

14. HALL, Stuart. A identidade cultural na pós-modernidade. Tradução: Tomaz Tadeu da Silva \&Guacira Lopes Louro. 11 ed. Rio de Janeiro: DP\&A, 2006.

15. MIGUEL, Luis Felipe. Da "doutrinação marxista" à" ideologia de gênero"-Escola Sem Partido e as leis da mordaça no parlamento brasileiro/From "Marxistindoctrination" to "genderideology": Escola Sem Partido (non-partisanschool) and gag laws in Braziliancongress. Revista Direito e Práxis, v. 7 , n. 15 , p. 590-621, 2016.

16. SEFFNER, Fernando. Atravessamentos de gênero, sexualidade e educação: tempos difíceis e novas arenas políticas. In: Reunião Científica Regional da ANPED. Curitiba: ANPED, 2016. 
17. SILVA, Tomaz Tadeu da. Documentos de identidade: uma introdução às teorias do currículo. $3^{a}$ ed. Belo Horizonte: Autêntica, 2009.

\section{Elvis Patrik Katz:}

Mestre em Educação pela Universidade Federal do Rio Grande - FURG, onde também cursou Licenciatura em História. Além disso, é membro do Grupo de Estudos em Educação, Cultura, Ambiente e Filosofia da Universidade Federal do Rio Grande - GEECAF/FURG, e professor de História na Rede Municipal de Ensino de Fontoura Xavier - RS.

\section{Andresa Silva da Costa Mutz:}

Doutora e Mestre em Educação na linha dos Estudos Culturais em Educação (2013/ULBRA e 2009/UFRGS).Licenciada em História (2004/UNISINOS). Professora Adjunta no Ensino Superior da Universidade Federal de Rio Grande/FURG. Na Graduação, é responsável pela disciplina Políticas Públicas da Educação, ofertada para todas as Licenciaturas da universidade. No Mestrado em Educação, encontra-se vinculada a Linda de Pesquisa Culturas, Linguagens e Utopias e sou responsável pelas disciplinas Teorias Pós-Críticas da Educação e O Conceito de Pedagogia Cultural e suas implicações no campo da Pesquisa Educacional Contemporânea. Pesquisadora do Núcleo de Estudos sobre Currículo, Cultura e Sociedade da Universidade Federal do Rio Grande do Sul NECCSO/UFRGS e no Grupo de Estudos em Educação, Cultura, Ambiente e Filosofia da Universidade Federal do Rio Grande - GEECAF/FURG.

\section{Como citar este documento:}

KATZ, Elvis Patrik; MUTZ, Andresa Silva da Costa. A CONSTRUÇÃO DE UMA IDENTIDADE DOCENTE DESEJÁVEL NO DISCURSO DO MOVIMENTO ESCOLA SEM PARTIDO. Reflexão e Ação, Santa Cruz do Sul, v. 26, n. 2, ago. 2018. ISSN 1982-9949. Disponível em: <https://online.unisc.br/seer/index.php/reflex/article/view/11756>.

Acesso

em: doi:http://dx.doi.org/10.17058/rea.v26i2.11756. 